\title{
Environmental Monitoring and Surveillance of Rodents and Vectors for Francisella tularensis Following Outbreaks of Human Tularemia in Georgia
}

\author{
Eka Elashvili, ${ }^{*}$ Ian Kracalik, ${ }^{2,3 *}$ Irma Burjanadze, ${ }^{4 *}$ Sophio Datukishvili, ${ }^{4}$ Gvantsa Chanturia, ${ }^{4}$ \\ Nikoloz Tsertsvadze, ${ }^{4}$ Levan Beridze, ${ }^{4}$ Merab Shavishvili, ${ }^{4}$ Archil Dzneladze, ${ }^{4}$ \\ Marina Grdzelidze, ${ }^{4}$ Paata Imnadze, ${ }^{4}$ Andrew Pearson, ${ }^{5}$ and Jason K. Blackburn ${ }^{2,3}$
}

\begin{abstract}
Tularemia is a re-emerging bacterial zoonosis, broadly distributed across the northern hemisphere. In Georgia, there is a history of human tularemia outbreaks dating back to the 1940s. In response to outbreaks, health officials initiated long-term field surveillance and environmental monitoring. The objective of our study was to obtain information from 57 years of field surveys to identify species that play a role in the occurrence Francisella tularensis subsp. holarctica in the environment in Georgia. We collected historical data on human outbreaks, field collections, population dynamics of the common vole (Microtus arvalis), and conducted surveys on small mammals and vectors from five regions in Georgia during 1956-2012. Bacterial isolation was conducted using standard culturing techniques, and isolation rates for species were obtained for a subset of years. We used a Spearman rank correlation to test for associations between the density of the common vole and isolation rates. From 1956 through 2012, there were four recorded outbreaks of human tularemia (362 cases). A total of 465 bacterial isolates of $F$. tularensis subsp. holarctica were obtained from 27 species and environmental samples. The number of isolations was highest in the common vole (M. arvalis; 149 isolates; $32 \%$ ) and Dermacentor marginatus ticks (132 isolates; 28\%); isolation rates ranged between $0-0.91 \%$ and $0-0.47 \%$, respectively. Population dynamics of the common vole were not correlated with the isolation rate. Given the history of tularemia re-emergence in Georgia, continued field surveys and environmental monitoring may provide an early indication of outbreak risk in humans. In conclusion, our findings provide evidence of longstanding foci of $F$. tularensis subsp. holarctica that are likely maintained by the common vole-tick cycle.
\end{abstract}

Key Words: Francisella tularensis—Human tularemia—Georgia—Microtus arvalis—Dermacentor marginatusVole-tick cycle.

\section{Introduction}

$\mathbf{T}$ Ularemia is a BaCterial zoOnOtic Disease broadly distributed across the Northern Hemisphere. The causative agent of the disease, Francisella tularensis, is thought to circulate in the environment among small mammals (primarily rodents and lagomorphs) with arthropods acting as vectors (Petersen and Schriefer 2005, Rossow et al. 2014).
Recently, tularemia has re-emerged in several European countries (Petersen and Schriefer 2005). Despite recent outbreaks and an increasing incidence in parts of Europe (Hestvik et al. 2015), the ecology of $F$. tularensis is still poorly understood.

In Georgia, there is history of tularemia outbreaks in humans dating back to the 1940s among soldiers at a military garrison in the Samtshke-Javakheti region. In response to this

\footnotetext{
${ }^{1}$ National Food Agency, Tbilisi, Georgia.

${ }^{2}$ Spatial Epidemiology and Ecology Research Lab, Department of Geography, University of Florida, Gainesville, Florida.

${ }^{3}$ Emerging Pathogens Institute, University of Florida, Gainesville, Florida.

${ }^{4}$ National Center for Disease Control and Public Health, Tbilisi, Georgia.

${ }^{5}$ University of Maryland, Maryland.

*These authors contributed equally to this work.
} 
outbreak and subsequent outbreaks (Fig. 1), the National Center for Disease Control and Public Health (NCDC) in Tbilisi, Georgia, began monitoring the re-emergence of human tularemia through surveillance of small mammals and vectors and the collection of environmental samples. Genetic characterization of bacterial isolates in Georgia showed all belonged to F. tularensis (type B) holarctica (Chanturia et al. 2011). A recent outbreak of water-borne tularemia in central Georgia has reiterated the need for continued monitoring and surveillance (Chitadze et al. 2009). The objective of our study was to analyze data from environmental sampling and field studies to trap small mammals and vectors aimed at isolating $F$. tularensis subsp. holarctica from several regions of Georgia to better understand the ecology.

\section{Materials and Methods}

Field surveys of small mammals and vectors were carried out by the NCDC during the period of 1956-2012. Generally, mammals were trapped with snap traps or Sherman-style live traps, and ticks were collected off of mammals or by flagging (Velijanashvili 1992). The study area $\left(23,837 \mathrm{~km}^{2}\right)$ included five regions in southeastern and eastern Georgia-Samtshke, Javakheti, Shida Kartli, Kvemo Kartli, and Kakheti. Mammals and ticks were identified to species and bacterial isolates were obtained via traditional culturing techniques (World Health Organization 2007). We derived the annual rate (\%) of bacterial isolation by species (number of isolates/total number collected); data for bacterial isolation rates were limited
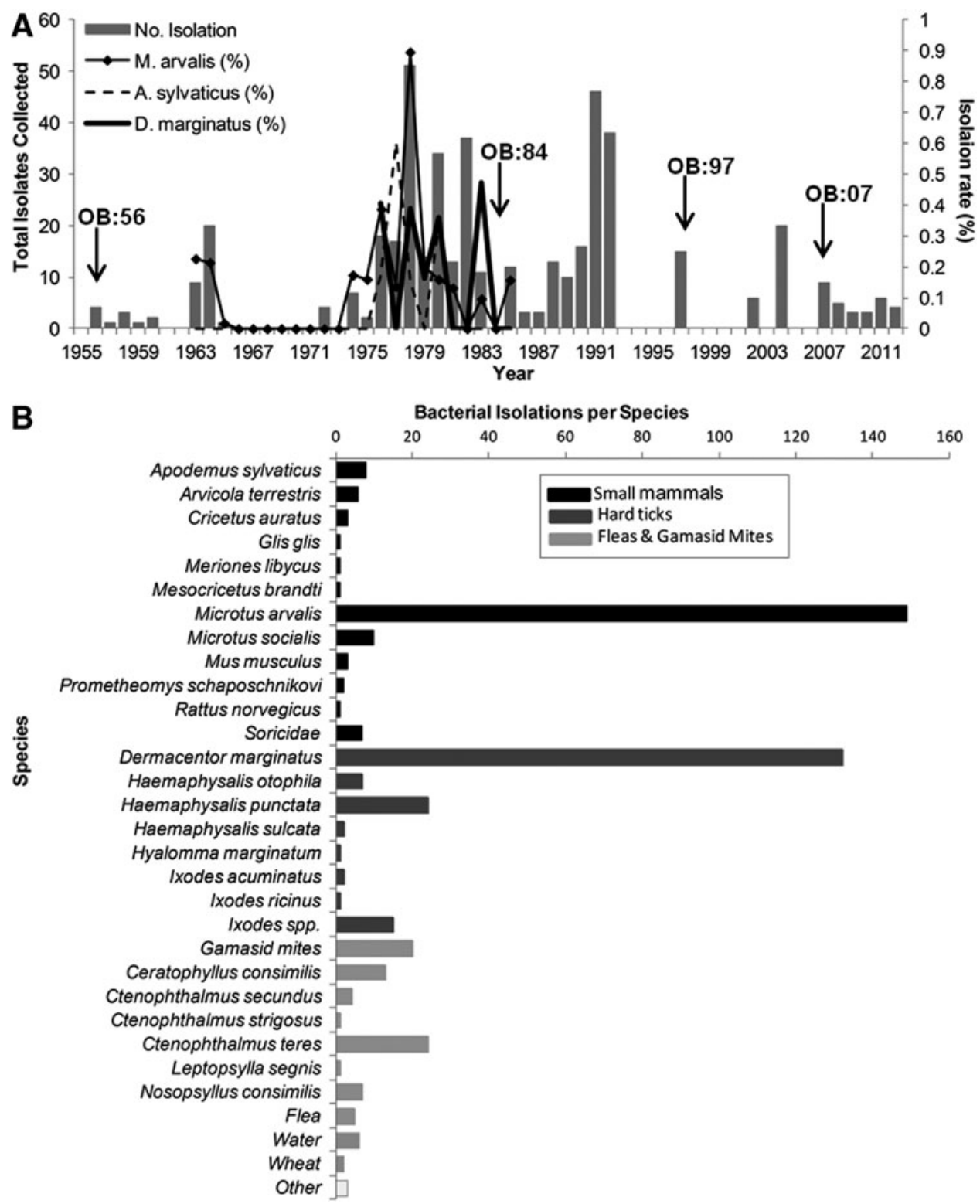

FIG. 1. (A) Total number of $F$. tularensis bacterial isolates collected from field surveys of small mammals and vectors and environmental sampling in Georgia 1956-2012. Rates of bacterial isolation by species were only available during 19631985. Primary species included Microtus arvalis, Apodemus sylvaticus, and Dermacentor marginatus. Outbreak years (OB) were recorded in 1956 (20 cases), 1984 (300 cases), 1997 (seven cases), and 2007 (35 cases). (B) Sample diversity of F. tularensis from small mammals (black bars), hard ticks (dark grey bars), and fleas/mites (light grey bars). 
to the Samtskhe-Javakheti region and to the period from 1963 to 1985.

We plotted, over time, the total number of bacterial isolates obtained, bacterial isolation rates, and the dates of human tularemia outbreaks obtained from historical records at the NCDC (sporadic human cases were not included). Here we define an outbreak as five or more cases in a single community. Density estimates of the common vole (Microtus arvalis) (derived from the number of active burrows/hectare) were collected in the Samtshke-Javakheti region during 1963-1985 (Velijanashvili 1992). To test for correlation between rates of bacterial isolation and common vole density, we used a Spearman rank test (SPSS, IBM, New York, NY).

\section{Results}

From 1956 to 2012, a total of 465 (range, 0-51) bacterial isolates of $F$. tularensis subsp. holarctica were obtained from field surveys (Fig. 1A). During 1963-1985, samples were obtained from 95,399 M. arvalis, 9349 Apodemus sylvaticus, 2917 Mus musculus, 1428 Arvicola terrestris, 3916 from 10 other small mammal species, 17,008 Ixodidae ticks, 800,966 fleas, and gamasid mites. Isolates were obtained from 27 different species and environmental samples (e.g., water, wheat); 194 isolates were obtained from small mammals, 184 from hard ticks, 75 from fleas/mites, and eight from environmental samples (Fig. 1B). Most small mammal isolates were obtained from rodents, although seven isolates were from shrews (Family: Soricidae). Common voles and Dermacentor marginatus ticks comprised the greatest number of isolates among small mammals and vectors, 32\% (149) and $28 \%$ (132), respectively. Rates of isolation during 1963-1985 are shown in Figure 1A. The percentage of isolation (total number collected) range for common voles was 0-0.91 (2448883 ) and D. marginatus was 0-0.47 (25-1206). Density of the common vole in the Samtshke-Javakheti region ranged between 22 and 196 animals/hectare (Fig. S1) (Supplementary Data are available at www.liebertonline/vbz/). There was no significant correlation between the rate of bacterial isolation and vole population density ( $\rho=0.282, p=0.19)$.

Human outbreaks of tularemia were recorded in 1956, 1984, 1997, and 2007 corresponding to human cases totals of 20, 300, 7, and 35, respectively (Fig. 1A).

\section{Discussion}

We obtained data from several thousand small mammals, vectors, and environmental samples collected from 57 years of field surveys in Georgia, resulting in the recovery of 465 bacterial isolates of $F$. tularensis subsp. holarctica from more than 27 species (Figs. 1 and S1). Initial surveillance efforts were driven by outbreaks of tularemia; our data also showed that bacterial isolates were routinely recovered in the absence of human reporting. These findings support evidence of longstanding natural foci of $F$. tularensis subsp. holarctica circulating among vectors and mammals in Georgia.

High numbers of bacterial isolates from rodents and vectors suggest they play a role in maintaining an enzootic cycle in Georgia, similar to findings from the former Soviet republics and Europe (Olsuf'ev and Rudnev 1960, Gyuranecz et al. 2012, Rossow et al. 2014). The common vole has been implicated in the spillover to other species and in the enzootic maintenance of the bacteria (World Health Organization
2007, Rossow et al. 2014, Hestvik et al. 2015). A study in Ukraine also identified long-standing foci of $F$. tularensis associated with the common vole and Dermacentor spp., among other species (Hightower et al. 2014).

In keeping with previous research, we identified repeated isolations of $F$. tularensis subsp. holarctica from the common vole and from blood feeding arthropods. Research in Hungary hypothesized that population dynamics of the common vole (2- to 3-year cycles) and peak densities drive the ecology and spillover of $F$. tularensis subsp. holarctica (Gyuranecz et al. 2012). We documented perturbations in the population density of the common vole, limited to one region, but did not find a correlation with isolation rates (Fig. S1). The common vole was the most abundant rodent trapped and had the highest rates of bacterial isolation in our study; however, the susceptibility of different mammalian species to $F$. tularensis may have influenced these findings (World Health Organziation 2007). The role of the common vole in facilitating spillover to other species in Georgia through contamination of the environment requires further investigation (World Health Organziation 2007, Gyuranecz et al. 2012, Rossow et al. 2014).

Interestingly, we identified several years of quiescence (no isolation) despite trapping and collecting several thousand specimens. This observation may be indicative of interepizootic periods. Recent research in Hungary suggested a European brown hare (Lepus europaeus)-tick cycle maintained $F$. tularensis during interepizootics (Gyuranecz et al. 2011). Although no testing of the European brown hare was conducted in our study, future surveys should focus on efforts to trap and test this species in Georgia.

Our findings provide evidence of long-standing foci of $F$. tularensis subsp. holarctica that may be maintained by a common vole-tick cycle. We used a more stringent method of determining positives via bacterial culturing, whereas using serology may have elicited a higher number of positive samples. Isolation rates of specimens and population dynamics of the common vole were only available for subsets of the study period, and more complete records in the future will provide a better understanding of the dynamics of $F$. tularensis. Given the history of tularemia re-emergence in Georgia, continued monitoring of small mammals, vectors, and environmental sampling may provide an early indication of outbreak risk in humans.

\section{Acknowledgments}

This work was funded by the US Defense Threat Reduction Agency's Cooperative Biological Engagement Program in Georgia through the GG-19 Project. J.K. Blackburn and I.T. Kracalik were supported through the DTRA Academic Engagement Program administered by Penn State University. This manuscript is dedicated to the memory of Dr. Ioseb Velijanashvili.

\section{Author Disclosure Statement}

No competing financial interests exist.

\section{References}

Chanturia G, Birdsell DN, Kekelidze M, Zhgenti E, et al. Phylogeography of Francisella tularensis subspecies holarctica from the country of Georgia. BMC Microbiol 2011; 11:139. 
Chitadze N, Kuchuloria T, Clark D, Tsertsvadze E, et al. Waterborne outbreak of oropharyngeal and glandular tularemia in Georgia: Investigation and follow-up. Infection 2009; 37: 514-521.

Gyuranecz M, Rigó K, Dán Á, Földvári G, et al. Investigation of the ecology of Francisella tularensis during an interepizootic period. Vector Borne Zoonotic Dis 2011;11:10311035.

Gyuranecz M, Reiczigel J, Krisztalovics K, Monse L, et al. Factors influencing emergence of tularemia, Hungary, 19842010. Emerg Infect Dis 2012; 18:1379.

Hestvik G, Warns-Petit E, Smith L, Fox N, et al. The status of tularemia in Europe in a one-health context: A review. Epidemiol Infect 2015: 143:2137-2160.

Hightower J, Kracalik IT, Vydayko N, Goodin D, et al. Historical distribution and host-vector diversity of Francisella tularensis, the causative agent of tularemia, in Ukraine. Parasites Vectors 2014; 7:453.

Olsuf'ev N, Rudnev G. Tularemia. Moscow, 1960 1960; Traslated into English.
Petersen JM, Schriefer ME. Tularemia: Emergence/re-emergence. Vet Res 2005; 36:455-467.

Rossow H, Sissonen S, Koskela KA, Kinnunen PM, et al. Detection of Francisella tularensis in voles in Finland. Vector Borne Zoonotic Dis 2014; 14:193-198.

Velijanashvili I. Tularemia on Meskhet-Javakheti Plateu. Dissertation (in Russian), 1992.

World Health Organization. World Health Organization Guidelines on Tularemia. Geneva: World Health Organization, 2007:125.

Address correspondence to: Jason K. Blackburn

Spatial Epidemiology \& Ecology Research Laboratory Department of Geography University of Florida 3141 Turlington Hall Gainesville, FL 32611

E-mail: jkblackburn@ufl.edu 